www.nature.com/bmt

\title{
Errata
}

\section{Psychosocial supportive care for children receiving stem cell transplantation: practice patterns across centers}

AC Sherman, S Simonton, U Latif, L Nieder, RH Adams and P Mehta

Bone Marrow Transplantation (2004) 34, 833. doi:10.1038/sj.bmt.1704731

Correction to: Bone Marrow Transplantation (2004) 34, 169-174. doi:10.1038/sj.bmt.1704546
This article was published under an incorrect subject heading. The correct subject heading should be 'Psychosocial Support'.

\section{Long-term remission of myelofibrosis following nonmyeloablative allogeneic peripheral blood progenitor cell transplantation in older age: the Scripps Clinic experience}

N Greyz, WE Miller, J Andrey and J Mason

\author{
Bone Marrow Transplantation (2004) 34, 833. The following sentence is published correctly below: \\ doi:10.1038/sj.bmt.1704732 \\ The patient's splenomegaly resolved and he remains free \\ of disease over 33 months post transplant with minimal \\ Correction to: Bone Marrow Transplantation (2004) 34, \\ 273-274. doi:10.1038/sj.bmt.1704578 \\ cGVHD involving oral mucosa that is under excellent \\ control on low-dose cyclosporine and budesonide.
}

